time of their removal, and did not again present the features so suggestive of tetany.

I regard this case as valuable, inasmuch as it tends to support the growing belief in the impossibility of drawing a hard-and-fast line between the so-called functional diseases of the nervous system. In this patient the neurotic diathesis was marked in every phase of her malady. Inheriting directly from her mother a legacy of nervous instability, what wonder that she should be prone to the development of nervous disorder, which found expression both in her psychical and physical processes. Whether the case be regarded as one purely distinctive of hysteria, or whether it be looked upon as one of hysteria in which a group of symptoms conforming to the type of tetany were superadded as a consequence of some other morbid process, is, $I$ think, a matter of speculation.

Lindfield, Sussex.

\section{TWO CASES OF CYSTITIS, WITH UNUSUAL COMPLICATIONS.}

BY GILBERT BARLING, B.S., F.R.C.S., ASSISTANT SURGEOY TO THE GENERAI HOSPITAI, BIRMINGHAY.

Case 1.-A gentleman, aged twenty-seven, consulted me in January last for frequent and painful micturition, which had been troubling him for a few days. My first note of him, made January 8th, was: Micturition twelve times in the last twenty-four hours; necessity for immediate expulsion when the demand arose; pain in the perineum and at the end of the penis after micturition; temperature practically normal. Urine faintly alkaline, but not ammoniacal ; sp. gr. 1018; a slight deposit of pus and mucus; albumen nearly one-half of a column. Microscopic examination showed pus and a few blood corpuscles, but no casts, after a most careful search. There was no oedema or headache, and except for the local trouble the patient felt little the matter with him. With complete rest in bed and milk diet he rapidly improved, and on Jan. 14th the micturition was less frequent and painful; the urine contained more pus, but no blood, and the albumen was only onefourth of a column, and there were still no casts to be found. $\mathrm{He}$ then commenced to take small doses of copaiba.-Jan. 17th: The albumen was reduced to onesixteenth of a column, and he was in all respects better.18th : Aching pain in the right knee joint, which was rather hot and swollen.-20th : Right knee full of fluid; slightly painful; no inflammatory blush over it. Left ankle slightly strollen. No fever; no sweating. Pulse 76. Joints fixed on a McIntyre's splint and covered with evaporating lotion.22nd: Urine almost free from pus; albumen one-eighth of a column. Micturition almost as in health. Joints much the same. Tongue furred. Anorexia. Pulse 80 ; temperature $99^{\circ}$.-25th: Right knee still very tense; left ankle better, but left knee distended with fluid, and similar to the condition of the right on Jan. 20th. No sweating or fever. Tongue very furred.-28th: Pus and albumen have disappeared from urine. Right knee and left ankle diminishing in size; left knee very tense.-31st: Phalangeal joint of left great toe red, swollen, and tender; other joints much better, and now treated with mild counter-irritation. Tongue still very furred.-Feb. 4th: All the joints better. Tongue cleaner. Desire for food returning.-20th: The swelling has disappeared from all the joints except the left ankle. The tongue is clean, and the urine healthy. Soon after this the patient went to the seaside, and resumed his business at the end of a month. There is no doubt that the attack was produced by exposure to the extreme cold at the end of December, 1886.

Case 2.-H- a labourer, aged forty, was in the General Hospital under my care in September, 1835, suffering from cystitis. His trouble commenced six months previously, when he was under treatment in a cottage hospital for fracture of the femur. Owing to his recumbent position he had difficulty in micturating, which ended in retention ten days after his admission. The bladder was emptied once with the catheter, and soon after he noticed blood in his urine, which became thick, and later contained pieces of grit. The hæmaturia continued until he came to the General Hospital, when he also complained of frequent micturition, pain in the perineum, and especially of pain in the glans penis after micturition. On sounding, patches of calculous matter were detected, some of them appearing to be fixed on the surface of the bladder. Rectal examination revealed no thickening of the base of the bladder. The pathologist, Dr. Bull, reported on the urine as follows: "Colour yellowish-red; alkaline; ammoniacal: specific gravity 1015; albumen half a column. Microscopic examination: Triple phosphates, blood, pus, vesical epithelium, and a few doubtful granular casts." After a week's rest in bed, with careful emptying of bladder and washing out with boracic acid solution, the condition of the urine had improved somewhat, the albumen had diminished to one-third, and prolonged search failed to find any casts; but the patient was much worn by pain and broken rest, so I performed the "Boutonnière" on Sept. 29th, partly to evacuate the small concretions that the sound detected, and partly for the purpose of draining the bladder A few grains of free calculous matter were removed, and $\operatorname{som} \theta$ adherent patches were scraped off; but the most important condition found was a patch of ulceration about two inches in diameter on the trigone and its neighbourhood. The ulcer was of considerable depth, and surrounded by numerous warty elevations coated with calculous matter, suggesting to my mind that I had to deal with a malignant growth; I therefore removed some of the warty parts for further examination, and secured a drainage tube in the bladder. Microscopic examination of the warts showed nothing but granulation tissue in various stages of development. On Oct. 5th the tube was removed, as it was beginning to annoy the patient, who otherwise made an excellent recovery, interrupted only by an attack of epididymitis on the eighth day. Un Oct. 22nd some urine passed by the urethra was examined; it was slightly ammoniacal, and contained a thick cloud of albumen, a little pus and blood, and some phosphatic crystals. A week later there were only a few pus-cells, and a trace of albumen in the urine, and the patient was discharged on Nov. 7th, reporting himself some weeks later as being perfectly well.

Remarks.- - I have described these two cases together, as they had in common what is, I believe, a very unusual condition in cystitis uncomplicated with nephritis-viz., severe albuminuria, which I presume was dependent upon a large serous exudation from the bloodvessels of the mucous membrane of the bladder, and perhaps of the upper urinary tract, or, in the second case, from the ulcerated bladder surface. The joint complication in the first case did not closely resemble either urethral arthritis or acute rheumatism, being of a much milder type than is generally noticed in the former, and without the severe pain, sweating, and fever of the latter. The rapid and complete recovery after drainage in the second case was most satisfactory.

\section{Clintial 筧otes:}

\section{MEDICAL, SURGICAL, OBSTETRICAL, AND} THERAPEUTICAL.

\section{A NOTE ON THE LOCAL TREATMENT OF PSORIASIS.}

By JoHN Kent SPENDER, M.D. LOND.,

PHYSICLAN TO THE ROYAL MINERAL WATER HOSPITAL, BATH.

I IMAGINE that dermatologists are coming to the conclusion that the more circumscribed a skin disease is the more is it a purely local affair, requiring to be treated mainly with outside methods. If a person has, for instance, two or three dull-red mahogany-looking patches of psoriasis, now and then perhaps somewhat inflamed, but always so abrupt in margin that a pen or pencil line can be drawn round them, we should think first and almost solely of remedies applied to the visible disease, whatever may seem fitting to be done as internal confederates and helps.

Now, if there be any disease for which thermal bathing is almost always successful, it is the common psoriasis diffusa when treated with the Bath mineral waters. Adults and children come who are "white as snow and scaly as hoar frost"; and without taking any drugs (usually so called) they often leave Bath in less than six woeks (unless the disease bo chronic and very defiant) with the skin physio- 
logically sound and texturally pure. Nothing within the range of what is termed balneo-therapeutics is more trustworthy than this. A contrast to this generalised condition of things was lately seen in an Irish gentleman sent to me by Mr. Malcolm Morris, who had on the skin of the pubes a symmetrical dark-red patch, absolutely dry and very irritable. The patient left Bath without much benefit; the lenient influence of a hot alkaline water did not penetrate far enough to alter the deep pigmentation of the dermal structures, although the hypertrophy of superficial layers of cuticle seemed to be modified and "tamed down." Shortly after this Mr. Morris told me that he quickly cured his patient's malady by a combination of chrysophanic acid and lanoline.

One of the objects of this short paper is to give my experience of Auspitz's method, which consists in creating an artificial cuticle or film with certain substances dissolved in chloroform or gutta-percha. ${ }^{1}$ This cuticle is made by discolving one part of purified gutta-percha in ten parts of chloroform, which forms an excellent medium for fixing the applicetion, as it adheres firmly and without alteration for several days. It is thin, chemically neutral, and does not cause tension or pain. Dr. Payne has further illustrated the subject in the last number but one of the St. Thomas's Hospital Reports. He proposes a solution of chrysarobin (20 grains) in a fluid ounce of liquor gutta-percha. This is to be painted with a brush on the affected places (from which the scales have been removed as much as possible by soft soap) once or twice a day, so as to form a perpetual film. The action is more rapid, and there is no staining of the clothes. The principle is capable of variation in detail, but Dr. Payne claims for the plan that it is specially neat and cleanly for the purposes of private practice. Chrysarobin thus applied, adds Dr. Payne, supersedes all other remedies. Perhaps this last assertion is too absolute, as there are not a few people who instinctively dislike any varnish which seals up the skin and shuts in the natural secretion of the smallest cutaneous area. Otherwise, I can heartily commend Dr. Payne's modification of Auspitz's method used within narrow limits. The principle has already been tested in the treatment of eczema. Under the protective guardianship of a gelatine enamel, irritation subsides, and a healthy epidermis is developed within a few days. Here everything depends upon the temporary exclusion of air, with all its impurities of dust and tribes of germs.

\section{INJURY OF THE HEAD, IMMEDIATELY FOLLOWED BY SYMPTOMS OF COMPRESSION ;} TREPHINING; RECOVERY.

BY GEo. Herbert WILliams, M.R.C.S. ENG., L.R.C.P. EdIN., LATE HOUSE-SURGEON, ROYAL INFIRMARY, MANCHESTER.

ON May 3rd, 1887, about 10 P.M., I was called to see A. W- a lad of nine, with the following history:-Two hours previously, the child had tripped at play and fallen on the left side of his head. He was, however, able to run home, where, complaining of pain, dimness of vision, and sickness, he was enjoined to lie down and rest.

On my arrival, two hours later, I found the patient lying on his back, and my attention was first directed to a contusion over the left temporal bone about the size of a Tangerine orange. No fracture could be felt at the seat of injury. The left side of the body was affected with clonic convulsions; the right hemiplegic; pupils widely dilated; conjunctive insensible to touch, and breathing stertorous. After a consultation it was decided at once to trephine over the sent of injury, as the only prospect of relief from imminent death. The coma was so profound that no anæsthetic was necessary. After carefully incising the periosteum, and turning it back, a circle of bone was removed, as near the seat of injury as possible, when a considerable amount of renous blood was immediately poured out. The finger was then introduced, and swept round the inside of the skull, but as no clot or spiculum of bone could be found, and the symptoms being still unrelieved, I nicked the dura mater, and incised it the length of the trephine wound, when the convulsions and hemiplegia almost simultaneously disappeared. The soft parts were then replaced, and the skin flaps brought together with a few points of suture, a drainage-tube being introduced, the length of the wound.

1 Annales de Dermatologie et de Syphilographie, vol, v., No. 1.
The little patient was then removed to bed, and slept soundly for about four hours.

On my next visit-ten hours after the operation-I found him sitting up in bed calling lustily for breakfast. From this date the recovery was rapid and satisfactory. On the twentieth day the wound was quite healed, with a fair deposit of new bone, and the boy was out at play.

Remarks. - I must admit that, as there was no fracture or depression, I expected to find a clot on the dura mater, which, as already stated, was not the case, and yet one can scarcely think that the venous blood that followed the removal of the circle of bone was sufficient in itself to relieve the right hemiplegia. It is just possible the left convulsions may have been caused by contrecoup; but whatever the true pathology of this interesting case may be, I feel convinced in my own mind that the well-marked relief was brought about by incising the dura mater, and thus relieving the intra-cranial pressure.

Lockwood, Huddersfield.

\section{POISONING BY LABURNUM SEEDS.}

By Sydnex H. A. Stephenson, M.B.Edrn.

ON March 23rd, 1887, a number of girls, who were convalescent from ophthalmia, went into their play-yard after their dinner at 12.30 P.M., where they picked up and ate some laburnum seeds. The seeds had been blown over into the yard from some neighbouring laburnum trees. The nurse in charge, on going into the yard at about 3 P.M., found a girl vomiting, and in the course of a fow minutes five other girls commenced to vomit; they were all very white, complained of pain in their heads, and were shivering. The nurse could ascertain no cause for their sudden and simultaneous illness, which she thought might be due to something they had eaten at dinner, and which had disagreed with them. When I saw the children at 3.30 P.M. they had been put to bed; they all denied having eaten anything in the play-yard, and it was with some difficulty that I elicited the real facts from the eldest of them. Their individual states were as follows:-

CASE 1.-Age twelve years. Had eaten two seeds, and had vomited four times. This patient was lying flat on her back in bed, shivering violently; her face was shrunken and her lips were very white. She answered questions in a whisper, and with difficulty; said that she had pain in her head. Her pupils were equally dilated, acting both to light and to accommodation. Pulse feeble, 124 per minute; temperature in axilla $98^{\circ}$.

CASE 2.-Age nine years. Had eaten four seeds, and had vomited three times. General state similar to the first case. Pupils active and dilated. Pulse 132 per minute; temperature $97^{\circ} 4^{\circ}$.

CASE 3.-Age six years. Had eaten one seed, and had vomited once. Was pale and shivering. Pupils dilated. Pulse 100 per minute; temperature $976^{\circ}$.

CASE 4.-Age eight years. Had eaten three seeds, and had vomited twice. Complained of great pain in her head. Pupils dilated. Pulse 106 per minute; temperature $97^{\circ}$.

CASE 5.-Age four years. Had eaten one seed, and had vomited three times. Pupils dilated. Had headache. Pulse 120 per minute; temperature $97^{\circ}$.

CASE 6.-Age five years. Had eaten one seed, and had vomited five or six times. Very pale, and shivering a great deal. Pupils dilated. Pulse 136 per minute; temperature $97 \cdot 2^{\circ}$

Two other children had eaten some (two or three) seeds. Neither of them had vomited; but both were very pale, had dilated pupils, rapid pulses, and temperatures below $98^{\circ}$. Later in the day, at 5 P.M., about two hours and a half after the time the rest of the children are supposed to have eaten the seeds, two other girls commenced to vomit, complained of headache, and had dilated pupils and rapid pulses. In all the cases the vomited matters consisted of particles of food mixed with brownish-coloured mucus, which in the first case was slightly tinged with blood. At 8 o'clock in the evening the sixth case was covered from head to foot with an eruption of large red patches, much resembling scarlatina. This had quite disappeared by 10 A.M. on the following morning. All the patients were well on March 25th. The treatment adopted was to inject ether hypodermically, and then to give large draughts of tepid 